\title{
Discussion on the application of multimedia teaching in clinical pharmacology
}

\author{
He Li ${ }^{a}$, Chunmei Wang ${ }^{b}$, Jinghui Sun ${ }^{c}$ Hongxia Sun ${ }^{d}$, Chengyi Zhang ${ }^{e}$, \\ Weijing Sun ${ }^{\dagger}$ and Jianguang Chen ${ }^{g^{*}}$
}

\author{
College of Pharmacy, Beihua University, Jilin City, 132013, China

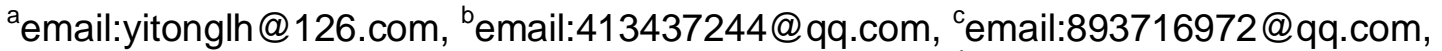

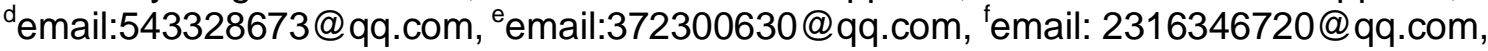 \\ g*email:644257703@qq.com, corresponding author,
}

"corresponding author

\begin{abstract}
Keywords: Multimedia teaching; Clinical Pharmacology; Network resource; Computer Abstract. The application of multimedia teaching methods in the teaching of clinical pharmacology is to focus on the improvement of education quality. The establishment of appropriate platform for clinical pharmacological teaching on the basis of network resources and the effective innovative teaching design by utilizing the network resource platform will achieve an optimization of the teaching effect. In this article, the thinking and application of multimedia teaching in the teaching process of clinical pharmacology in our school are summarized. Multimedia teaching is a new type of teaching and an inevitable trend in the development of education. It is important to look for the teaching difficult points, explore the teaching reform innovation points, utilize the diversity of multimedia information to give play to its advantages in clinical pharmacology teaching, and establish the multimedia teaching platform for clinical pharmacology with the help of network information. The application of multimedia teaching has shown a bright prospect. However, how to research the teaching? How to edit teaching materials suitable for multimedia teaching? How to make great progress in multimedia teaching methods? All these need our further in-depth study.
\end{abstract}

\section{Introduction}

The combination of multimedia teaching with teaching reform is a new type of training in the innovative ability, and can make the teaching content more creative and practical. What is important in the application of multimedia teaching is the teaching design. The application value of a good resource can be significantly improved through an appropriate teaching design. Clinical pharmacology is a new branch of science developed rapidly in recent decades, and a study of the action law of drugs in the human body and the interaction between the human body and drugs, in which the human body is taken as the study subject; on the base of pharmacology and clinical medicine, it deals with pharmacokinetics, pharmacodynamics, drug adverse reactions and drug interaction law, and is considered a bridge between the basic medicine and clinical medicine, and a link of pharmacy to clinical medicine[1-4]. In this article, the thinking and application of multimedia teaching in the teaching process of clinical pharmacology in our school are summarized.

\section{Multimedia teaching- a new type of teaching in the future and an inevitable trend in the development of education}

The superiority and the practicability of multimedia teaching can be reflected in many aspects, such as experimental classes, skills training and teaching practice. It can be widely used in teaching, and has shown a positive significance in the quality-oriented education, skills training and cultivation of creative thinking ability. In the teaching practice, for example, drugs used for the treatment of hypertension involves some aspects such as microscope, abstract and mechanism, in which it is difficult to be repeated and practiced with a high cost, and for a rare case, it is difficult to practice on spot and on patients' bodies, and demonstrate the teaching content. However, an intellectualization 
teaching method can be used to conduct a new teaching for clinical pharmacology so that the students can both review the some associated basic knowledge such as physiology and pathology, and integrate the knowledge on medication principles of essential hypertension and secondary hypertension to see and learn the relevant knowledge in their leaning process for the realization of the purpose to understand. It is the multimedia teaching technology that has shown has a vivid and visual feature to make some boring and hard teaching contents become interesting and colorful.

Since it can make teaching the information content and form re-decomposed, processed, transformed, conversed and rebuilt, multimedia teaching may create a new content presentation and form suited to the current teaching content and levels, and make students gain new knowledge from these changes or verify the knowledge, which can be difficultly achieved by other teaching methods. How to rationally use intelligent teaching methods and get out of misunderstanding of multimedia teaching to avoid a mere formality should be an issue to be solved. Based on teaching experiences for years, a summary is made as follows: First, depending on the teaching requirements, to take different multimedia teaching methods to scientifically design functions of a multimedia teaching system, such as the type of experimental operation, data tools and online teaching, etc., for giving full play advantages of the various functions and integrating the advantage and the effect of multimedia; secondly, to optimize multimedia teaching contents, multimedia courseware to maxi9mize the effect of limited classroom teaching time; thirdly, to make full use of the characteristics of multimedia for the innovation, keep up with the new theory and the research achievement of technology, solicit views of the course teachers and students to obtain first-hand information on teaching and new theoretical understanding, and explore a road for the virtuous cycle corresponding to the preparation of teaching quality products and the discovery of teaching innovation points; finally, while utilizing various characteristics of the multimedia teaching, to focus on the accuracy, simplicity and practicality just suitable for the teaching, and create simple and colorful multimedia teaching materials with less and concise network resources as possible, in order to achieve the best teaching effect and the purpose to benefit both teaching and learning.

\section{To look for teaching difficult points to explore teaching reform innovation points}

In the application of multimedia courseware, not only is the form of multimedia adopted, but also the inherent characteristics of multimedia are taken into account. The awareness on the application of multimedia should be strengthened to enhance the innovation, exchange ideas of the multimedia teaching and practice the learning methods, for achieving a great improvement of the teaching effectiveness and learning quality.

\section{Close relationship between the application of multimedia and the innovation in teaching reform}

The close relationship between the application of multimedia and the innovation in teaching reform is manifested primarily in the full play of multimedia flexibility under the guidance of modern education ideas and theories, which is important to exploring new teaching reform policies, establishing new thinking ways of learning and teaching, inspiring the spirit of creatively learning and applying and looking for innovative points of the teaching reform. An advanced teaching media only serves for a correct education thought, its creative world can be vast and free, with a living soul. No matter what kind of media, its values in the teaching can be identified only when this types of media effectively plays an role that can not be replaced by other ways in teaching practice to make teachers and students firsthand feel its advantages, practicability, scientificity and advancement in teaching and learning.

\section{Changes in teaching idea}

The core of teaching has been changed, that is, the transformation from the traditional teacher-centered, classroom-centered and textbook-centered education approach to a student-centered learning one, to strengthen individual practice-centered idea for the transformation from passive to active education and the exam-oriented to quality education. This view has provided a favorable support for the innovation of teaching reform to allow students to comprehensively 
improve their quality, enhance their ability to receive continuing education and better adapt to the fierce competition of this era, which is also a higher demand for talents in the current society.

\section{Utilizing the diversity of multimedia information to give play to its advantages in clinical pharmacology teaching}

With advances in technology, a wealth of information is emerging, so that the new requirements for modern teaching are how to allow the students to get more information within the limited time, and shorten the information processing and conversion process from the image to the abstract, and then from the abstract to the image in the brain, to fully convey the intent of teaching. And the value of multimedia teaching resides not only in its strong presentation of image, but also in the control of random flexible presentation of information, and one of more prominent characteristics of multimedia is "flexible", which can avoid the monotony defect of TV teaching materials to make the teachers teach the students in a student-centered teaching scenario, simulate the results of irrational medication with the related software in the classroom for improving the effect of classroom learning, activating the classroom atmosphere, and stimulating the students' enthusiasm and initiative, which is an effective form advocated in modern education to strengthen the exchange of teaching and learning, and mobilize student's initiative. In the process of multimedia teaching, classroom teachers should consider mutual complementation of classroom and after-class teaching forms to consciously select the content of classroom teaching, make focal points stand out and save teaching hours, which are where the teaching innovative points are. For example, when the medication in special populations are introduced in the classroom, the contents related to anatomy, physiology, pathophysiology and pharmacology can be integrated with the software, and effects of the drugs can be analyzed and summarized from different levels, so that the knowledge structure can be extended in both breadth and depth. The modification of multimedia teaching materials can be completed by teachers themselves and even by some students who like to participate in it, so that the multimedia teaching may facilitate the teachers to get hold of the classroom teaching atmosphere flexibly, actively promote the student-centered idea, further strengthen the leading awareness unifying proactive education and active participation, and update many stale contents in the teaching.

Furthermore, the exchange of teaching and learning should be strengthened in the classroom to help teachers accurately and timely use all types of information, and analyze and answer the classroom contents, based on the feedback information from the students, such as questioning and responses in the classroom. This will ensure not only the standardability, systematicness and organization of teaching, but also the autonomy, diversity and flexibility to some extent, so that the teaching contents will become more rich and colorful. With the support of all the multimedia characteristics, the classroom teaching form can be varied, so that the relationship between teaching and learning will be closer and harmonious, which may not only promote the students' active learning, but also place greater demands on the teachers to open up their teaching ideas and enrich the teaching contents.

\section{Establishment of multimedia teaching platform for clinical pharmacology with the help of network information}

The application of multimedia teaching and the surge of network resources have built a broad platform for the teaching of clinical pharmacology. To play a huge potential for multimedia teaching , only in the extensive network of search-related content, teaching materials, can greatly promote the new way of classroom teaching and collaborative learning education.

To take advantage of network resources is the theme of the 21 st century. Scientific and technological network resources are mainly derived from the famous medical research institutions or universities at home and abroad. In this way, a wider range of information resource sharing can be achieved. With the help of network resources, students can understand learning contents more widely and profoundly, their learning thinking is broader, learning methods are more diverse, intelligent culture is more efficient, leading to a more efficient learning. In addition, the learning of a real-time 
interactive computer multimedia teaching resources can be achieved, in which students and teachers exchange information timely, ask and answer questions, give and receive instruction, to achieve the effect of face to face teaching to some extent. This is an interactive teaching in another sense.

In short, the application of multimedia teaching has shown a bright prospect, how to research teaching by properly utilizing network resources? How to study the writing of teaching materials, How to edit teaching materials suitable for multimedia teaching? How to make great progress in multimedia teaching methods? All these need our further in-depth study. In the process of teaching, it is necessary to carefully design, reasonably combine and cleverly utilize multimedia and other media to give play to their comprehensive values. Meanwhile, a wide variety of setbacks and problems encountered in multimedia teaching should be handled objectively and rightly, to explore new teaching methods, develop teaching models to meet the current education, open and inspire teaching thinking, and strengthen the awareness of multimedia teaching, for the unification of the exploration and innovation.

\section{References}

[1]J.S. Li, X.G. Zhang, J. Chu, et al. Design and development of emr supporting medical process management, J. J Med. Syst. 36(2012) 1193-1203.

[2]F.F. Eroy, Improving technique survival in peritoneal dialysis:what is modifiable ,J. Perit. Dial. Int. 29(2009) 74-77.

[3]M.H. Imanieh, S.M. Dehghani, A.R. Sobhani, et al. Evaluation of problem-based learning in medical students' education, J. J. Adv. Med. Educ. Prof. 2(2013) 1-5. 